\title{
Quantifying the effects of mutations on receptor binding specificity of influenza viruses
}

\section{Wei Hu}

Department of Computer Science, Houghton College, Houghton, USA.

Email:wei.hu@houghton.edu

Received 7 January 2010; revised 11 January 2010; accepted 15 January 2010.

\begin{abstract}
Hemagglutinin (HA) of influenza viruses is a cylindrically shaped homotrimer, where each monomer comprises two disulfide-linked subdomains HA1 and HA2. Influenza infection is initiated by binding of HA1 to its host cell receptors and followed by the fusion between viral and host endosomal membranes mediated by HA2. Human influenza viruses preferentially bind to sialic acid that is linked to galactose by an $\alpha 2,6$-linkage $(\alpha 2,6)$, whereas avian and swine influenza viruses preferentially recognize $\alpha 2,3$ or $\alpha$ $2,3 / \alpha 2,6$. For animal influenza viruses to cross host species barriers, their HA proteins must acquire mutations to gain the capacity to allow human-to-human transmission. In this study, the informational spectrum method (ISM), a bioinformatics approach, was applied to identify mutations and to elucidate the contribution to the receptor binding specificity from each mutation in HA1 in various subtypes within or between hosts, including 2009 human H1N1, avian H5N1, human H5N1, avian H1N1, and swine H1N2. Among others, our quantitative analysis indicated that the mutations in HA1 of 2009 human H1N1 collectively tended to reduce the swine binding affinity in the seasonal H1N1 strains and to increase that in the pandemic H1N1 strains. At the same time, they increased the human binding affinity in the pandemic H1N1 strains and had little impact on that in the seasonal H1N1 strains. The mutations between the consensus HA1 sequences of human H5N1 and avian H5N1 increased the avian binding affinity and decreased the human binding affinity in avian H5N1 while produced the opposite effects on those in human H5N1. Finally, the ISM was employed to analyze and verify several mutations in HA1 well known for their critical roles in binding specificity switch, including E190D/G225D in H1N1 and Q192R/ S223L/ Q226L/ G228S in H5N1.
\end{abstract}

Keywords: Binding Specificity; Discrete Fourier Transform; Electron-Ion Interaction Potential; Entropy; Hemagglutinin; Influenza; Informational
Spectrum Method; Mutation; Receptor

\section{INTRODUCTION}

Influenza A viruses are classified into different subtypes based on the viral surface proteins hemagglutinin (HA) and neuraminidase (NA). The initial step in the influenza infection is the binding of HA to sialylated glycan receptors on the host cells. HA is also the primary target for the immune response in the infected host. Human and swine influenza viruses are derived from avian viruses, facilitated by regular close contact among humans, birds, and pigs [1]. The past three influenza pandemics, the Spanish flu (H1N1) in 1918, the Asian flu (H2N2) in 1957, and the Hong Kong flu (H3N2) in 1968, all had arisen from a reassortment from avian, swine, and human viruses. The current 2009 influenza pandemic was caused by a swine-origin $\mathrm{H} 1 \mathrm{~N} 1$ virus. The adaptation of the virus to a new host entails the compatibility between host and virus genetic requirements to allow efficient replication and sustained transmission. The host barrier for influenza viruses to transmit in humans is multigenic, however, the receptor specificity of HA proteins is a key determinant.

The binding preference of influenza virus HAs affects the host specificity for infection. In general, human influenza viruses bind preferentially to $\alpha 2,6$ receptors, avian influenza viruses tend to bind to $\alpha 2,3$ receptors, and swine influenza viruses can bind to either $\alpha 2,6$ receptors or both $\alpha 2,6$ and $\alpha 2,3$ receptors, primarily based on differences in the amino acids in the HA receptor binding domain (RBD). The RBD of $\mathrm{HA}$ in various influenza subtypes has three structural elements in common, one $\alpha$-helix (190-helix) and two loops (130-loop and 220-loop). Different hosts express diverse SA isomers, i.e., $\alpha 2,3$ linkages in the gut of waterfowl, $\alpha 2,3$ and $\alpha 2,6$ linkages in the lung and intestinal epithelium of chickens, and $\alpha 2,6$ linkages in the upper respiratory epithelium and $\alpha 2,3$ and $\alpha 2,6$ linkages in the lower respiratory epithelium of humans [2].

A change of binding preference is essential for cross species transfer, which involves mutations in HA to alter its glycan receptor preference [3]. It is hypothesized that 
to facilitate efficient human transmission, mutations in $\mathrm{HA}$ are required to increase $\alpha 2,5$ binding and at the same time to decrease $\alpha 2,3$ binding [4]. A variety of mutations that can shift receptor preference of HA proteins have been identified.

In a study of receptor specificity of influenza $\mathrm{A} / \mathrm{H} 5$ viruses [5], all but two isolates exhibited high affinity to $\alpha 2,3$ receptors. The two isolates with a unique $\mathrm{S} 223 \mathrm{~N}$ change in HA demonstrated decreased affinity to $\alpha 2,3$ and moderate affinity to $\alpha 2,6$ receptors. Another study showed that introduction of the mutation Q192R enhanced the binding of HA in $\mathrm{H} 5 \mathrm{~N} 1$ to $\alpha 2,6$ receptors, and introduction of both mutations Q192R and S223N increased the binding preference significantly. Residue 192 is close to the 190 helix, and residue 223 is part of the 220 loop, where it is feasible for them to influence the binding affinity [6]. As for the H2, H3, H4, and H9 HAs, two substitutions Q226L and G228S are mainly responsible for the switch from avian to human binding [3,7,8,9].

Residues 138, 186, 190, 194, 225, 226, and 228 can modulate the binding affinity of H1N1 HA proteins, and two residues 190 and 225 play key dominant roles in binding affinity $[10,11]$. The sequences of the RBD of avian $\mathrm{H} 1$ viruses maintain a Glu at position 190 and a Gly at 225 (H3 numbering), while the human $\mathrm{H} 1$ viruses generally have an Asp at both positions 190 and 225. It is known that E190D and G225D mutations in H1 viruses can shift binding patterns from avian to human type. In the five 1918 H1N1 HA sequences, three have a D190 and a D225 with $\alpha 2,6$ affinity, and two have a D190 and a G225 with mixed $\alpha 2,6 / \alpha 2,3$ specificities [12]. In general, mutations D190/D225 favor a2,6 receptors in humans, D190/G225 like $\alpha 2,6$ and $\alpha 2,3$ receptors in swine, and E190/G225 prefer $\alpha 2,3$ receptors in avian [13]. The biochemical analysis in [14] quantified the multivalent HA-glycan interactions, and showed the effects of these mutations on glycan binding amplified by multivalency.

To date, the symptoms of $2009 \mathrm{H} 1 \mathrm{~N} 1$ are mild. The fear is that the virus may continue to mutate to bring about another more lethal outbreak in the subsequent months as the 1918 Spanish flu. In [15] two representative 2009 H1N1 HA sequences, A/California/4/2009 and $\mathrm{A} /$ Hamburg/5/2009, were shown to bind to both $\alpha 2,6$ and $\alpha 2,3$ receptors with some minor differences in a carbohydrate microarray analysis, as predicted in [16]. There were three amino acid mutations between these HA sequences: S83P, A197T, and V321I, which might account for these differences in binding. These findings suggested that no major change in binding affinity is necessary for pandemic virus to acquire human binding patterns, and the dual binding to $\alpha 2,6 / \alpha 2,3$ receptors is one contributor to the greater virulence of the pandemic virus than seasonal flu virus.

There were two other recent reports on the mutations of the 2009 H1N1 virus. The first report [17] located the potential mutations and strongly co-mutated positions in
NA. The second report [18] focused on HA and the interaction between HA and NA. The mutations of HA in 2009 H1N1 were found and mapped to the 3D homology model of $\mathrm{H} 1$, and the mutations on the five epitope regions on $\mathrm{H} 1$ were identified. With help from the results of the first study, two co-mutation networks were uncovered, one in HA and one in NA, where each mutation in one network co-mutates with the mutations in the other network across the two proteins HA and NA. These two networks residing in HA and NA separately may provide a functional linkage between the mutations that can change the drug binding sites in NA and those that can affect the host immune response or vaccine efficacy in HA.

In references $[19,20]$ the informational spectrum method (ISM) [21] was applied to investigate the interaction between HA and its receptors, which showed that HA1 of different flu subtypes encodes one highly conserved domain that might be determinants of HA binding affinity. The study in [22] extended the results in references $[19,20]$ by identifying multiple domains in HA1 associated with each receptor interaction pattern. These conserved domains in HA1 might be used to identify new therapeutic targets for drug development.

In references $[19,20]$ it was found that the consensus informational spectrum (CIS) of HA1 of influenza strains have the following characteristic dominant peaks at different IS frequencies as presented in Table 1. In this study, $\mathrm{F}(0.295)$ will be referred to as pandemic human H1N1 receptor interaction frequency, $\mathrm{F}(0.055)$ as swine receptor interaction frequency, $\mathrm{F}(0.076)$ as avian receptor interaction frequency, and $\mathrm{F}(0.236)$ as seasonal human $\mathrm{H} 1 \mathrm{~N} 1$ receptor interaction frequency. In addition to the dominant peak at IS frequencies in each subtype, there are secondary peaks at various IS frequencies [19,20,22].

Viral evolution can help influenza viruses surmount species barriers. Once adapted in a new host, they still need to continue their evolution to fit better in the new environment. In this study, we sought to investigate the effects of mutations in HA1, either within or between hosts, on binding preference shift through a quantitative analysis, the ISM. The analysis performed in this study was based on the observation that several influenza viruses display dual specific recognition of receptors with $\alpha 2,6$ or $\alpha 2,3$ linkages. Our goal was to utilize the ISM to uncover the amino acid polymorphisms in HA1 within or between hosts and to measure their contribution to the binding specificity switch quantitatively.

Table 1. Characteristic IS frequencies of HA proteins in 2009 $\mathrm{H} 1 \mathrm{~N} 1$, swine $\mathrm{H} 1 \mathrm{~N} 1 / \mathrm{H} 1 \mathrm{~N} 2$, avian $\mathrm{H} 5 \mathrm{~N} 1$, and seasonal human H1N1.

\begin{tabular}{ccccc}
\hline Subtype & $\begin{array}{c}2009 \\
\text { H1N1 }\end{array}$ & $\begin{array}{c}\text { Swine } \\
\text { H1N2/H1N1 }\end{array}$ & $\begin{array}{c}\text { Avian } \\
\text { H5N1 }\end{array}$ & $\begin{array}{c}\text { Seasonal } \\
\text { human H1N1 }\end{array}$ \\
\hline Frequency & $\mathrm{F}(0.295)$ & $\mathrm{F}(0.055)$ & $\mathrm{F}(0.076)$ & $\mathrm{F}(0.236)$ \\
\hline
\end{tabular}




\section{MATERIALS AND METHODS}

\subsection{Sequence Data}

All HA sequences were retrieved from the Influenza Virus Resource (http://www.ncbi/nlm.nih.giv/genomes/ FLU/FLU.html) of the National Center for Biotechnology Information (NCBI) on November 20, 2009. Only the full length and unique sequences were selected. There were 450 HA sequences of human 2009 H1N1, 201 HA sequences of human H5N1 from 1979 to 2009, 1228 HA sequences of avian H5N1 from 1959 to 2009, 78 HA sequences of avian H1N1 from 1976 to 2008, and 83 HA sequences of swine H1N2 from 1980 to 2009. All the sequences used in the study were aligned with MAFFT [23].

\subsection{Entropy}

In information theory [24], entropy is a measure of disorder or randomness associated with a random variable. Let $x$ be a discrete random variable that has a set of possible values $\left\{a_{1}, a_{2}, a_{2}, \ldots a_{n}\right\}$ with probabilities $\left\{p_{1}, p_{2}, p_{3}, \ldots p_{n}\right\}$ where $P\left(x=a_{i}\right)=p_{i}$. The entropy $\mathrm{H}$ of $x$ is

$$
H(x)=-\sum_{i} p_{i} \log p_{i}
$$

In the current study, each of the $\mathrm{n}$ columns in a multiple sequence alignment of a set of $\mathrm{HA}$ sequences of $\mathrm{N}$ residues is considered as a discrete random variable $x_{i}$ $(1 \leq i \leq \mathrm{N})$ that takes on one of the $20(\mathrm{n}=20)$ amino acid types with some probability. $H\left(x_{i}\right)$ has its minimum value 0 if all the residues at position $i$ are the same, and achieves its maximum if all the 20 amino acid types appear with equal probability at position $i$, which can be verified by the Lagrange multiplier technique. A position of high entropy means that the amino acids are often varied at this position. $H\left(x_{i}\right)$ measures the genetic diversity at position $i$ in our current study. A brief overview of the extensive applications of entropy in sequence analysis, in particular the flu virus sequences, can be found in [17].

\subsection{Important Sites in HA}

Although there is a great variation due to high selection pressure in the HAl sequences of various flu subtypes, the active site of HA1 is well conserved, which is located in a cleft composed of the residues $91,150,152$, $180,187,191$, and 192. The three amino acids at positions 187, 191 and 192 are a part of the 190 helix. The active site cleft of HA is formed by its right edge (131_GVTAA) and left edge (221_RGQAGR) (H1 numbering), which are also commonly referred to as the 130 loop and 220 loop, respectively $[25,26]$.

\section{RESULTS}

\subsection{Mutations within Hosts}

\subsubsection{Human H1N1}

After visual inspection of the alignment of 2009 human H1N1 HA1 sequences, there was either an Asp (single letter code D) at position 127 in the pandemic strains or a deletion at position 127 in the seasonal strains. Since Asp had the highest EIIP value of 0.128 [22], this deletion at position 127 might influence the DFT spectral distribution. Of the 450 HA1 sequences of 2009 human H1N1 collected, there were 345 pandemic H1N1 sequences with an Asp at position 127 and 105 seasonal H1N1 sequences with a deletion at position 127.

The CIS of the pandemic H1N1 HA1 sequences were plotted in Figure 1(a), which have a dominant peak at frequency $\mathrm{F}(0.295)$ (pandemic human $\mathrm{H} 1 \mathrm{~N} 1$ binding), and the CIS of the seasonal H1N1 HA1 sequences were plotted in Figure 1(b), which have a dominant peak at frequency $F(0.055)$ (swine binding). According to the ISM concepts, this demonstrated the different receptor binding patterns of the 2009 pandemic and seasonal H1N1 strains. Figure 2 illustrated the consensus sequences of the pandemic H1N1 strains (human binding preference) and seasonal H1N1 strains (swine binding preference), respectively.

There were 90 amino acid substitutions between the two consensus HA1 sequences of human and swine binding characteristics (Figure 2 and Table 2). Based on

Table 2. Mutations between swine and human bindings in HA1 sequences of 2009 H1N1.

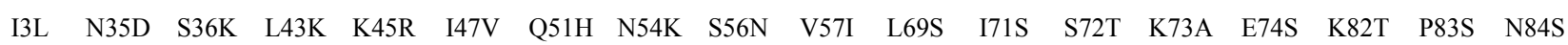

P85S E86D H94D A96I E120T -127D S128T V129N T130K S133T S135A S137P N139A E141A S142K R146K L149I T152V

G153K N155G G156N L157S N160K A166I N167D E170G V179I P183S N184T I185S V186A K189Q T190S H193Q T194N E195A

N196D S200F V202G H205R R208K T211K K216I I227M L234V T239K I241T N245T I249V A250V L257M S258E G260N F261A

N267I N269D A270T M272V D273H K274D D276N A277T K278T Q283K V295I V298I E302K R308K A310T M314L V315A I321V
} 


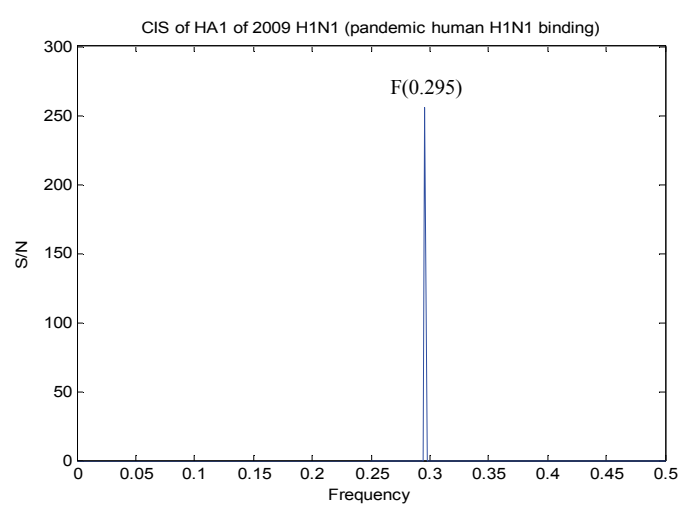

(a)

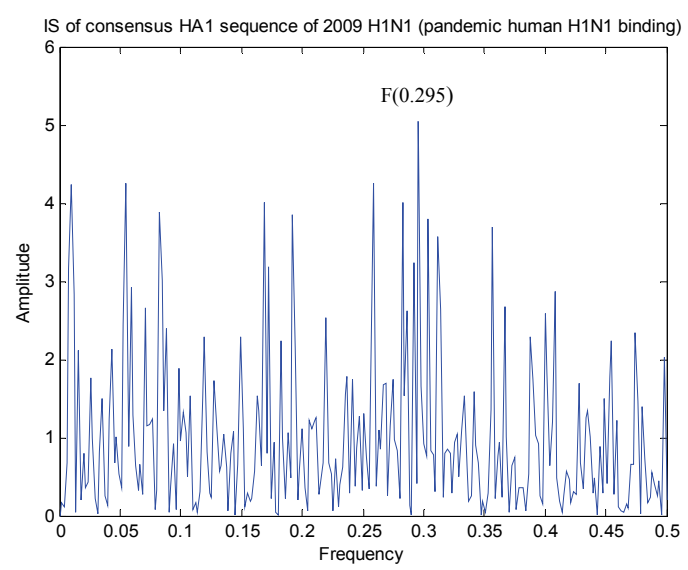

(c)

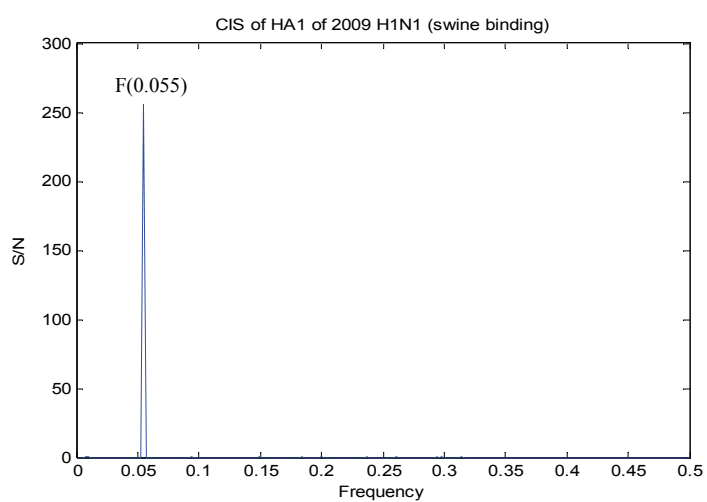

(b)

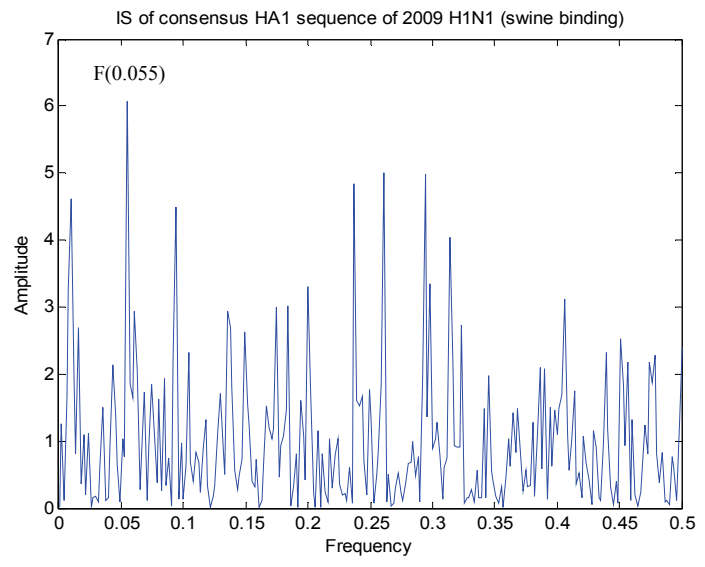

(d)

Figure 1. (a) CIS of HA1 of 2009 pandemic H1N1 (pandemic human H1N1 binding); (b) CIS of HA1 of 2009 seasonal H1N1 (swine H1N1 binding); (c) IS of HA1 of 2009 pandemic H1N1 (pandemic human H1N1 binding); (d) IS of HA1 of 2009 seasonal H1N1 (swine H1N1 binding).

the ISM theory, the mutations in HA1 that increased the amplitude of $F(0.295)$ and decreased that of $F(0.055)$ would contribute the switch of receptor binding affinity from swine to human type. The variation amount of the amplitudes of $\mathrm{F}(0.295)$ and $\mathrm{F}(0.055)$ was calculated for each of the 90 mutations applied to each consensus HA1 sequence, swine binding or human binding. The top 32 mutations that resulted in the amplitude change at frequency $\mathrm{F}(0.295)$ or $\mathrm{F}(0.055)(\Delta \mathrm{A})$ more than $6 \%$ were listed in Table 3, suggesting that these mutations might be critical for modulating the binding preferences between swine and humans. In general, increasing the amplitude at one frequency $\mathrm{F}(0.295)$ or $\mathrm{F}(0.055)$ will decrease that at another frequency, but there were several exceptions. Three "hot spots", D94, D196, and D274, found in [19] contributed to the amplitudes at frequencies $F(0.295)$ and $F(0.055)$ with different amounts (Table 3). There were a mutation $\mathrm{T} 152 \mathrm{~V}$ at the binding site, and two mutations S133T and S135A at the right edge of the binding pocket, which were not listed in Table 3 because their $\Delta \mathrm{A}$ value was relatively small. Table 3 also contained several mutations of interest, which were T130K and S137P near the right edge of the binding pocket, and P183S, N184T, I185S, H193Q, T194N, and N196D near the active site.

In [18], three networks of co-mutations in HA of 2009 H1N1 were uncovered. The first one had residues 269, 276 , and 309 , the second one had residues $34,167,195$, and 268 , and the third one had residues 129,210 , and 238, where each residue co-mutated with others in the same network. Two pairs of mutations N167D/E195A and N269D/D276N in Table 2 were part of the aforementioned co-mutation networks discovered in [18]. Their individual and combined effects on $\Delta \mathrm{A}$ were listed in Table 4, with the second pair having a much larger impact on the binding preference than the first. There were two clusters of mutations in Table 2, where the first was located at positions from 152 to 170 , and the 
second at positions from 257 to 278 . The first cluster of mutations was contained in a pandemic human H1N1 receptor recognition domain $(150: 174)$ with the characteristic IS frequency at $F(0.295)$ found in [22]. Prompted by this finding, we searched for a similar domain near the second cluster, and found a new domain (246:286) of swine binding characteristic with the IS dominant peak at frequency $\mathrm{F}(0.055)$ (Figure 3 ).

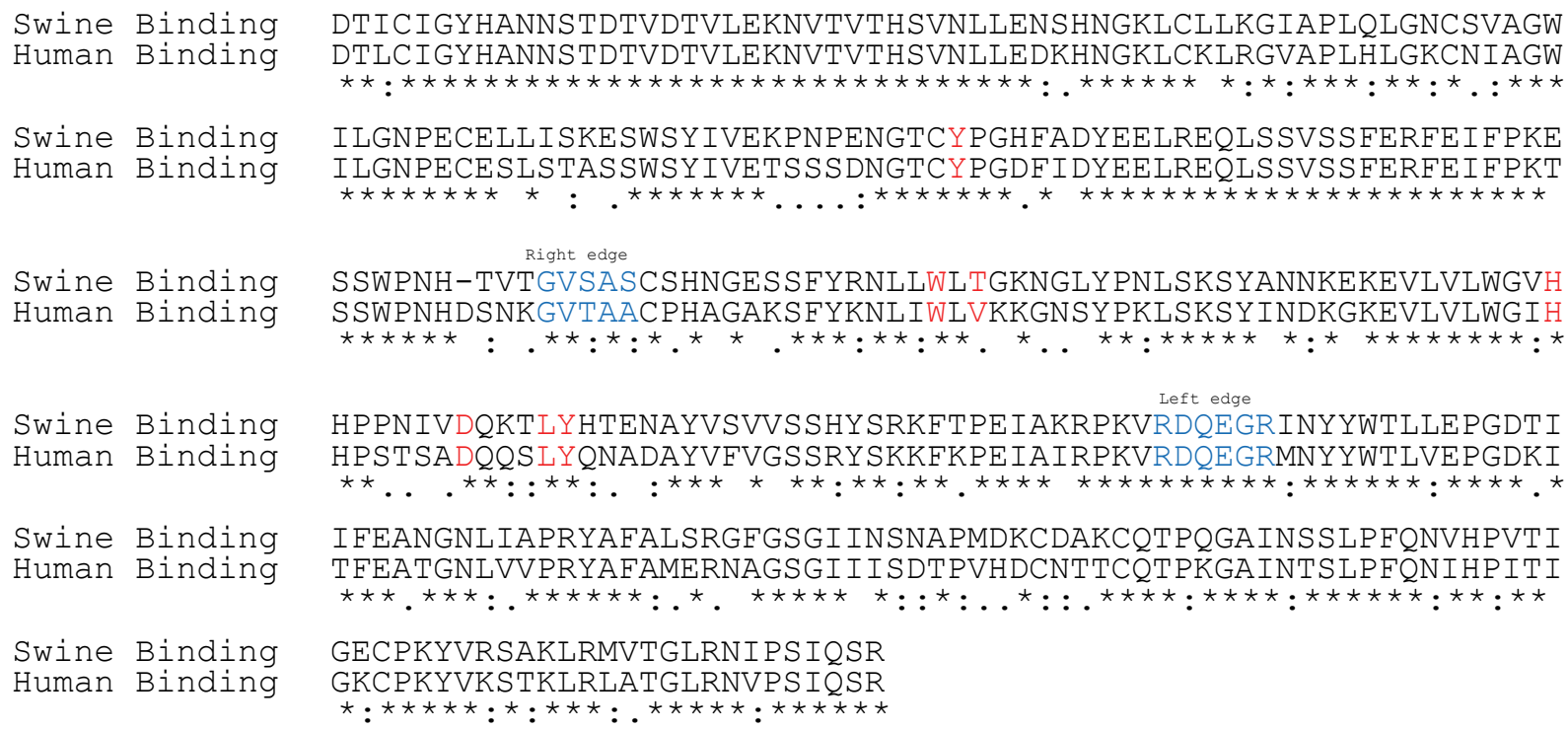

Figure 2. Alignment of two consensus HA1 sequences of 2009 pandemic H1N1 (pandemic human H1N1 binding) and 2009 seasonal H1N1 (swine binding). The binding sites in HA are colored in red, the left and right edges of the binding cleft in blue.

Table 3. Changes of amplitudes of IS frequencies by top 32 mutations with large $\Delta$ A value in HA1 of 2009 H1N1.

\begin{tabular}{|c|c|c|c|c|}
\hline \multirow[b]{2}{*}{ Mutations } & \multicolumn{2}{|c|}{ Mutating Consensus HA1 Sequence of Swine Binding Patterns } & \multicolumn{2}{|c|}{ Mutating Consensus HA1 Sequence of Human Binding Patterns } \\
\hline & $\Delta \mathrm{A}[\mathrm{F}(0.055)] \%$ & $\Delta \mathrm{A}[\mathrm{F}(0.295)] \%$ & $\Delta \mathrm{A}[\mathrm{F}(0.055)] \%$ & $\Delta \mathrm{A}[\mathrm{F}(0.295)] \%$ \\
\hline N35D & 11.025 & 10.814 & -12.123 & -12.608 \\
\hline $\mathrm{K} 45 \mathrm{R}$ & -6.935 & 2.2999 & 8.1835 & -6.5807 \\
\hline $\mathrm{S} 56 \mathrm{~N}$ & -8.347 & -9.5275 & 10.448 & 0.093211 \\
\hline L69S & 1.1681 & 6.0652 & -0.70212 & -8.5586 \\
\hline I71S & 7.0299 & -9.42 & -7.5854 & 4.8054 \\
\hline E74S & 8.719 & -3.4947 & -9.8488 & 9.1621 \\
\hline $\mathrm{K} 82 \mathrm{~T}$ & -6.9799 & -4.8104 & 8.282 & -5.4234 \\
\hline P83S & -7.2536 & 7.4623 & 8.6929 & -1.423 \\
\hline N84S & -7.7848 & 0.88042 & 9.617 & 10.047 \\
\hline H94D & 6.739 & 5.3039 & -7.8366 & 14.058 \\
\hline E120T & -9.7084 & 2.2202 & 11.954 & -6.9883 \\
\hline $\mathrm{T} 130 \mathrm{~K}$ & -5.6997 & 7.272 & 5.909 & 5.7416 \\
\hline S137P & 7.0562 & 8.6072 & -8.3647 & 4.9132 \\
\hline $\mathrm{T} 152 \mathrm{~V}$ & 0.49754 & -6.8741 & -3.6229 & -9.9879 \\
\hline L157S & -9.3159 & -5.0672 & 10.114 & -9.6759 \\
\hline P183S & 6.6852 & 7.4566 & -8.2446 & 2.4515 \\
\hline N184T & 10.495 & 0.64815 & -11.043 & -10.482 \\
\hline $\mathrm{I} 185 \mathrm{~S}$ & 9.2299 & -10.327 & -8.6728 & 3.045 \\
\hline H193Q & -6.1179 & 4.6131 & 6.9435 & 3.7993 \\
\hline T194N & 10.605 & -4.89 & -9.7841 & 10.506 \\
\hline N196D & -8.4752 & -0.04744 & 6.2191 & 16.521 \\
\hline $\mathrm{N} 245 \mathrm{~T}$ & -5.3848 & 8.7494 & 9.7128 & -10.596 \\
\hline $\mathrm{L} 257 \mathrm{M}$ & 9.7014 & -7.2577 & -10.573 & 10.05 \\
\hline $\mathrm{S} 258 \mathrm{E}$ & -8.2999 & -8.3169 & 8.7374 & 4.3745 \\
\hline N269D & -9.1545 & 8.9086 & 6.7895 & -12.176 \\
\hline $\mathrm{M} 272 \mathrm{~V}$ & -3.1046 & -9.3909 & 7.0087 & 9.0809 \\
\hline D273H & -6.1335 & 7.448 & 11.253 & -0.73203 \\
\hline K274D & 7.7964 & -10.052 & -10.303 & 12.443 \\
\hline $\mathrm{D} 276 \mathrm{~N}$ & -12.437 & -3.5437 & 13.913 & 9.3104 \\
\hline A277T & 5.1287 & -7.8075 & -4.4654 & 6.8946 \\
\hline R308K & -0.59247 & 7.761 & 3.5286 & -6.9255 \\
\hline M314L & -7.2075 & 5.2935 & 6.3119 & -5.2079 \\
\hline Total & -27.0553 & 0.9764 & 40.4485 & 29.9315 \\
\hline
\end{tabular}


Table 4. Changes of amplitudes of IS frequencies by mutations contained in the co-mutation networks in 2009 H1N1 discovered in [18].

\begin{tabular}{ccccc}
\hline & \multicolumn{2}{c}{$\begin{array}{c}\text { Mutating Consensus HA1 Sequence } \\
\text { of Swine Binding Patterns }\end{array}$} & \multicolumn{2}{c}{$\begin{array}{c}\text { Mutating Consensus HA1 Sequence } \\
\text { of Human Binding Patterns }\end{array}$} \\
\hline Mutations & $\Delta \mathrm{A}[\mathrm{F}(0.055)] \%$ & $\Delta \mathrm{A}[\mathrm{F}(0.295)] \%$ & $\Delta \mathrm{A}[\mathrm{F}(0.055)] \%$ & $\Delta \mathrm{A}[\mathrm{F}(0.295)] \%$ \\
\hline N167D & 0 & 0 & 0 & 0 \\
E195A & -2.674 & -3.7307 & 2.1705 & -0.36167 \\
N167D, E195A & -2.6740 & -3.7307 & 2.1705 & -0.3617 \\
N269D & -9.1545 & 8.9086 & 6.7895 & -12.176 \\
D276N & -12.437 & -3.5437 & 13.913 & 9.3104 \\
N269D, D276N & -20.8003 & 4.3377 & 21.7617 & -3.6715 \\
\hline
\end{tabular}

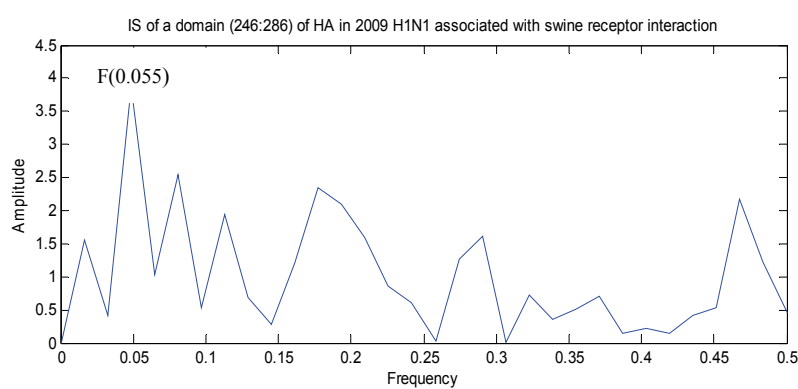

Figure 3. IS of one domain (246:286) of swine binding characteristic in HA1 of 2009 H1N1.

\subsubsection{Avian H5N1}

Although the whole set of HA1 sequences in avian H5N1 ( $\mathrm{n}=1228)$ displayed the CIS dominant peak at frequency $\mathrm{F}(0.076)$ (Figure 4(a)), there were several

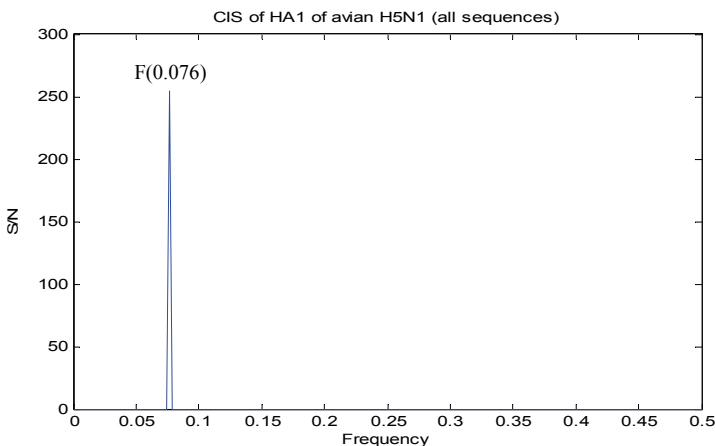

(a)

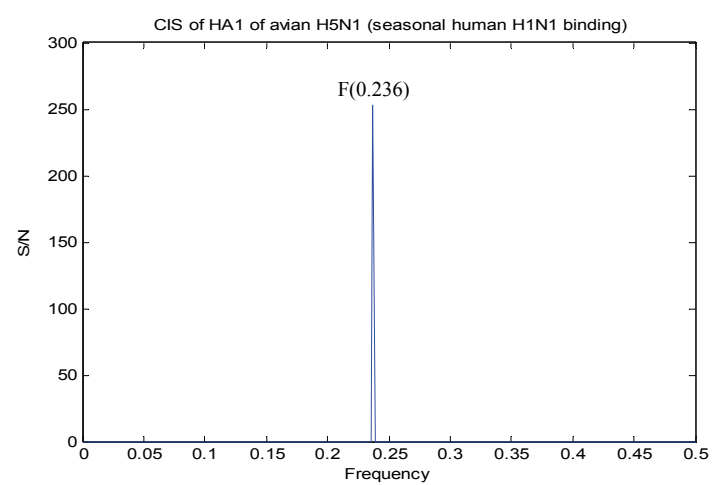

(b)

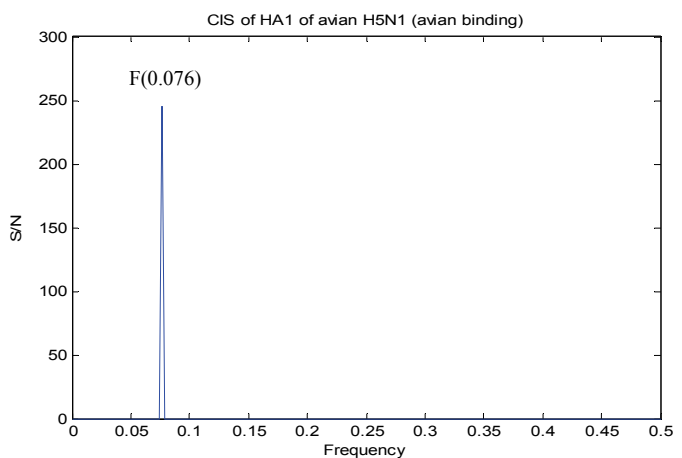

(c)

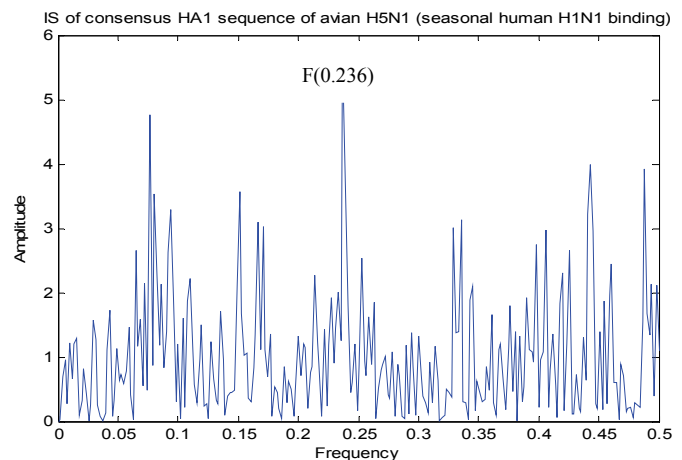

(d)

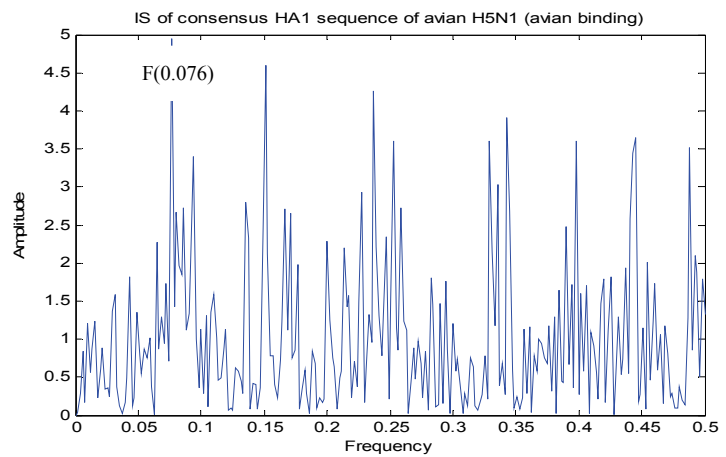

(e)

Figure 4. (a) CIS of consensus of all HA1 sequences of avian H5N1. (b) CIS of consensus HA1 sequence of avian $\mathrm{H} 5 \mathrm{~N} 1$ with seasonal human H1N1 binding. (c) CIS of consensus HA1 sequence of avian H5N1 with avian binding. (d) IS of consensus HA1 sequence of avian $\mathrm{H} 5 \mathrm{~N} 1$ with seasonal human H1N1 binding. (e) IS of consensus $\mathrm{HA} 1$ sequence of avian $\mathrm{H} 5 \mathrm{~N} 1$ with avian binding. 
HA1 sequences in the dataset that had a higher IS peak at frequency $\mathrm{F}(0.236)$ than that at the frequency $\mathrm{F}(0.076)$. Bases on this observation, the whole set of HA1 sequences in avian H5N1 collected were divided into two subsets. One had the IS dominant peak at frequency $\mathrm{F}(0.076)$, referred to as avian binding subset $(n=949)$, and the other had the IS dominant peak at frequency $F(0.236)$, referred to as human binding subset $(n=279)$. The CIS of these two subsets of HA1 sequences were plotted in (b) and (c) of Figure 4, and the IS of their consensus HA1 sequences were plotted in (d) and (e) of Figure 4, respectively. A total of 11 amino acid changes between the two consensus HA1 sequences of avian binding and human binding were found, and the resulting amplitude variation from each mutation was computed (Table 5). There were several mutations near the active site: D154N, N155S, A156T, and R189K.

\subsubsection{Avian H1N1}

For avian $\mathrm{H} 1 \mathrm{~N} 1$, we used the same strategy as for avian $\mathrm{H} 5 \mathrm{~N} 1$ to divide the whole set of HA1 sequences $(n=78)$ in this subtype into two subsets according to different binding patterns (human $(n=19)$ vs. avian $(n=59))$ as reflected by two different IS characteristic frequencies $(\mathrm{F}(0.295)$ vs. $\mathrm{F}(0.282))$ (Figure 5). Between the two consensus HA1 sequences of avian $(\mathrm{F}(0.282))$ and human $(\mathrm{F}(0.295))$ binding, there was only one mutation N121S (Table 6). The ISM was applied to quantify this mutation's contribution to the amplitude variation of the consensus HA1 sequence in each binding characteristics (Table 6).

For H1N1 viruses, the substitutions E190D/G225D were essential for avian virus HA to acquire human virus receptor specificity [13]. Here ISM was employed to verify this fact numerically (Table 7).

Table 5. Changes of amplitudes of IS frequencies by each mutation between avian and human binding patterns in HA1 of avian H5N1.

\begin{tabular}{ccccc}
\hline & \multicolumn{2}{c}{$\begin{array}{c}\text { Mutating Consensus HA1 Sequence } \\
\text { of Avian Binding Patterns }\end{array}$} & \multicolumn{2}{c}{$\begin{array}{c}\text { Mutating Consensus HA1 Sequence } \\
\text { of Human Binding Patterns }\end{array}$} \\
\hline Mutations & $\Delta \mathrm{A}[\mathrm{F}(0.076)] \%$ & $\Delta \mathrm{A}[\mathrm{F}(0.236)] \%$ & $\Delta \mathrm{A}[\mathrm{F}(0.076)] \%$ & $\Delta \mathrm{A}[\mathrm{F}(0.236)] \%$ \\
\hline L71I & 0 & 0 & 0 & 0 \\
I83A & -2.7308 & 3.8849 & 2.6972 & -3.2926 \\
R140K & -7.8143 & 5.2052 & 8.2224 & -4.3565 \\
D154N & -14.371 & 5.9825 & 15.75 & -3.3428 \\
N155S & 6.3122 & 9.7463 & -5.5234 & -8.0289 \\
A156T & 1.9481 & 4.9408 & -1.3726 & -3.7429 \\
R189K & 0.21422 & -7.9896 & 0.36709 & 7.2805 \\
N252Y & -5.9842 & 3.5318 & 6.173 & -3.0255 \\
T262A & 0 & 0 & 0 & 0 \\
I282M & 4.7565 & 10.576 & -4.6209 & -8.6614 \\
G323R & 11.348 & -8.0717 & -10.859 & 7.048 \\
Total & -6.3212 & 27.8086 & 10.8338 & -20.1221 \\
\hline
\end{tabular}

Table 6. Changes of amplitudes of IS frequencies by each mutation between avian and human binding patterns in HA1 of avian H1N1.

\begin{tabular}{ccccc}
\hline & \multicolumn{2}{c}{$\begin{array}{c}\text { Mutating Consensus HA1 Sequence } \\
\text { of Avian Binding Patterns }\end{array}$} & \multicolumn{2}{c}{$\begin{array}{c}\text { Mutating Consensus HA1 Sequence } \\
\text { of Human Binding Patterns }\end{array}$} \\
\hline \multirow{2}{*}{ Mutation } & $\Delta \mathrm{A}[\mathrm{F}(0.282)] \%$ & $\Delta \mathrm{A}[\mathrm{F}(0.295)] \%$ & $\Delta \mathrm{A}[\mathrm{F}(0.282)] \%$ & $\Delta \mathrm{A}[\mathrm{F}(0.295)] \%$ \\
\hline $\mathrm{N} 121 \mathrm{~S}$ & -15.7142 & 18.6251 & 18.6439 & -15.7008 \\
\hline
\end{tabular}

Table 7. Changes of amplitudes of IS frequencies by mutations E190D/G225D.

\begin{tabular}{cccc}
\hline \multicolumn{4}{c}{ Mutating Consensus HA1 Sequences of Avian H1N1 } \\
\hline Mutations & $\Delta \mathrm{A}[\mathrm{F}(0.282)] \%$ & $\Delta \mathrm{A}[\mathrm{F}(0.295)] \%$ & Dominant Peak Frequency \\
\hline E190D & -13.2024 & 13.0862 & $\mathrm{~F}(0.282)$ \\
G225D & -10.4239 & -0.6548 & $\mathrm{~F}(0.282)$ \\
E190D,G225D & -22.8997 & 11.7994 & $\mathrm{~F}(0.295)$ \\
\hline
\end{tabular}




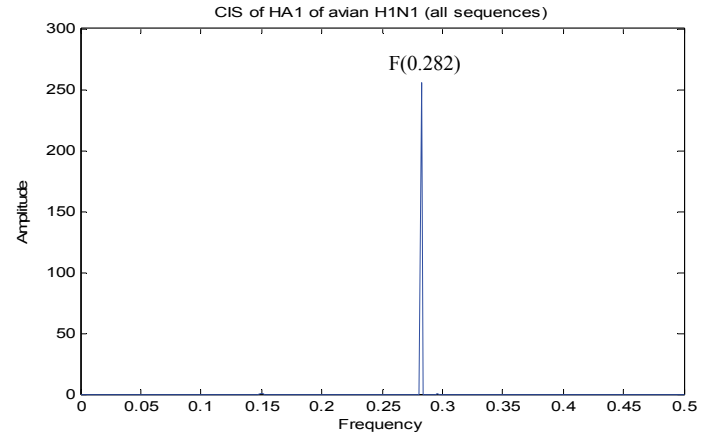

(a)

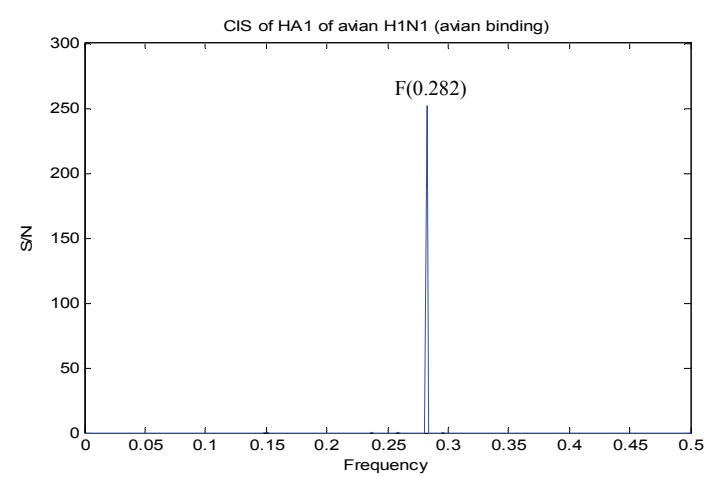

(b)

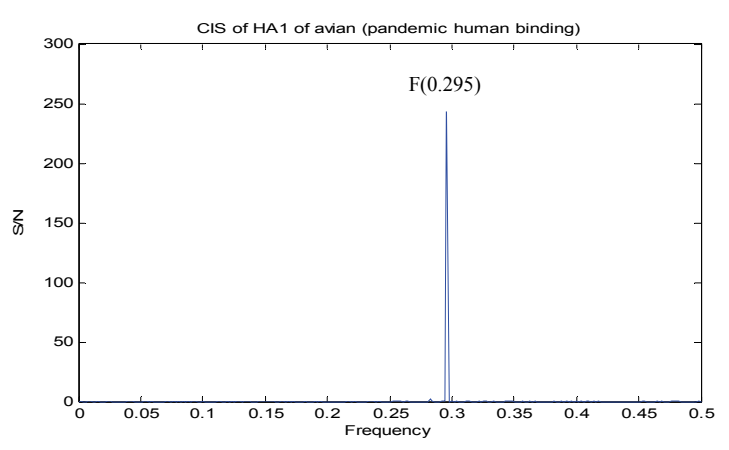

(c)

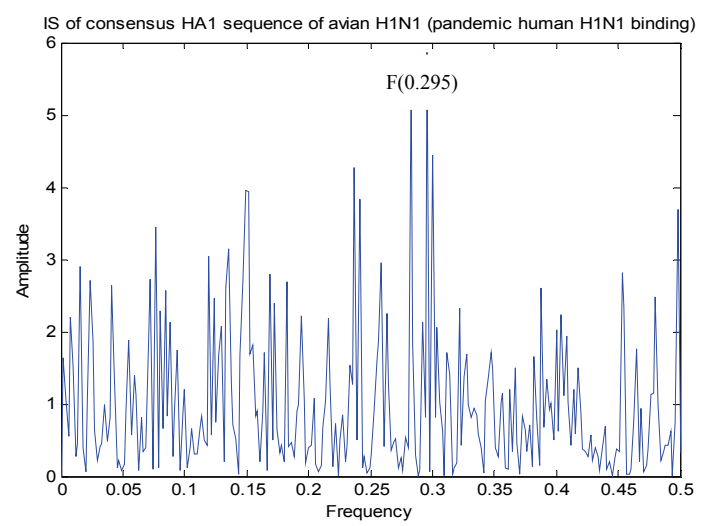

(d)

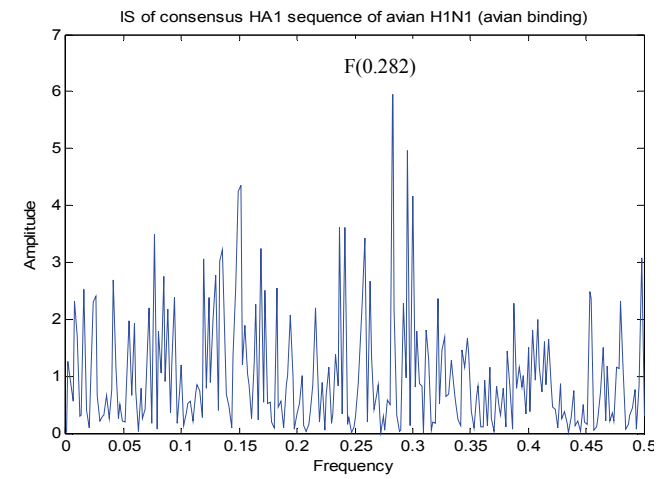

(e)

Figure 5. (a) CIS of consensus of all HAl sequences of avian H1N1; (b) CIS of consensus HA1 sequence of avian H1N1 with pandemic human H1N1 binding; (c) CIS of consensus HA1 sequence of avian H1N1 with avian binding; (d) IS of consensus HA1 sequence of avian H1N1 with pandemic human H1N1 binding; (e) IS of consensus HA1 sequence of avian H1N1 with avian binding.

\subsubsection{Swine H1N2}

For swine H1N2, we used the same strategy as for avian $\mathrm{H} 5 \mathrm{~N} 1$ to divide the whole set of HA1 sequences $(\mathrm{n}=82)$ in this subtype into two subsets according to different binding patterns (human $(\mathrm{n}=45)$ vs. swine $(\mathrm{n}=37)$ ) as reflected by two different IS characteristic frequencies $(F(0.295)$ vs. $F(0.055))$ (Figure 6). The comparison of the two consensus HA1 sequences (human vs. swine) revealed 14 mutations, and the ISM was applied to quantify each mutation's contribution to the amplitude variation of the consensus HA1 sequence in each binding characteristics (Table 8). There were several mutations near the active site: N184T, R189Q, and T190S, and near the edges of the binding pocket: E127D, E224A, and $\mathrm{R} 131 \mathrm{~K}$.

\subsection{Mutations between Hosts}

\subsubsection{H1N1 and Swine H1N2}

The $2009 \mathrm{H} 1 \mathrm{~N} 1$ virus has its origin as a reassortant from a triple-reassortant virus circulating in North American swine and Eurasian avian-like swine H1N1, with its HA from the classical swine influenza viruses.

The comparison of the consensus HA1 sequences of $2009 \mathrm{H} 1 \mathrm{~N} 1$ and swine H1N2 found 24 mutations. The ISM was applied to find the changes made by each mutation in the amplitude of IS of each consensus HA1 sequence (Table 9). Mutations K130R and E224A were near the edges of the binding pocket. There were three mutations at residues 71,211 , and 216 presented in Tables 3,9 , and 10 , implying their importance in determining binding preferences of swine H1N2 and 2009 H1N1. 


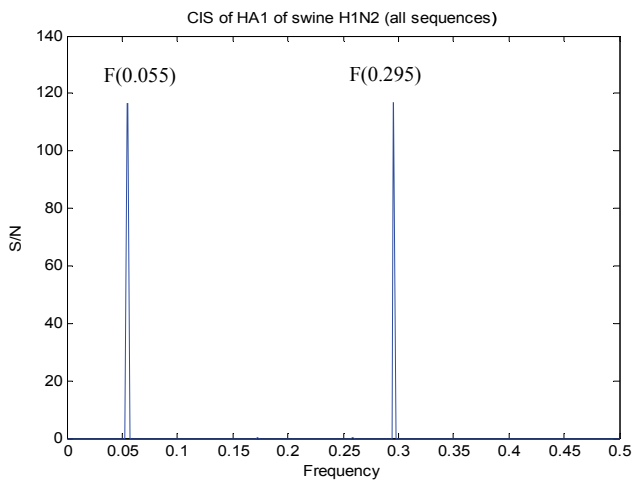

(a)

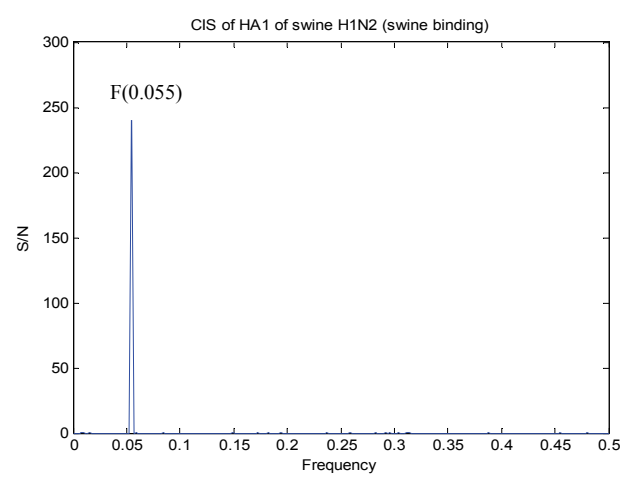

(b)

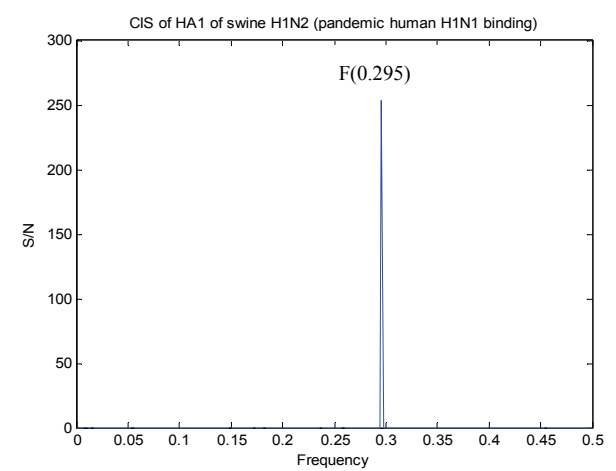

(c)

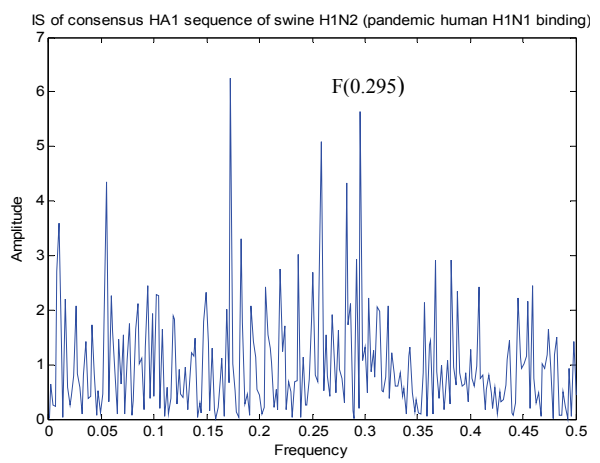

(d)

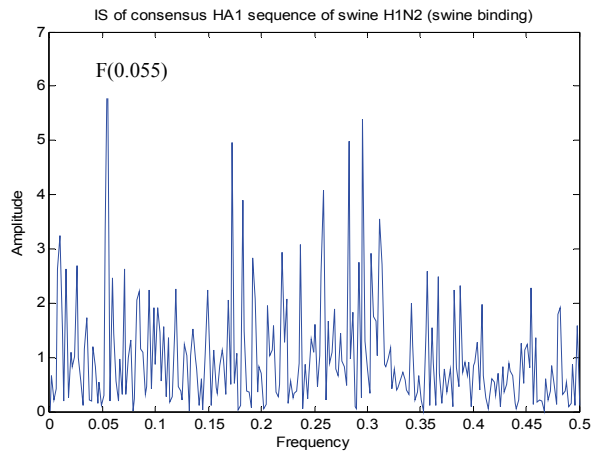

(e)

Figure 6. (a) CIS of consensus of all HA1 sequences of swine H1N2; (b) CIS of consensus HA1 sequence of swine H1N2 with pandemic human H1N1 binding; (c) CIS of consensus HA1 sequence of swine H1N2 with swine binding; (d) IS of consensus HA1 sequence of swine H1N2 with pandemic human H1N1 binding; (e) IS of consensus HA1 sequence of swine H1N2 with swine binding.

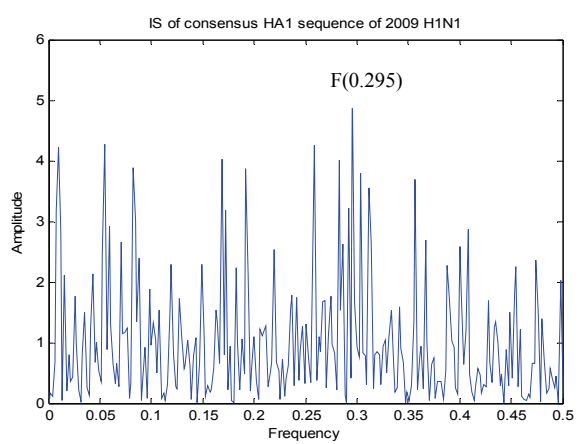

(a)

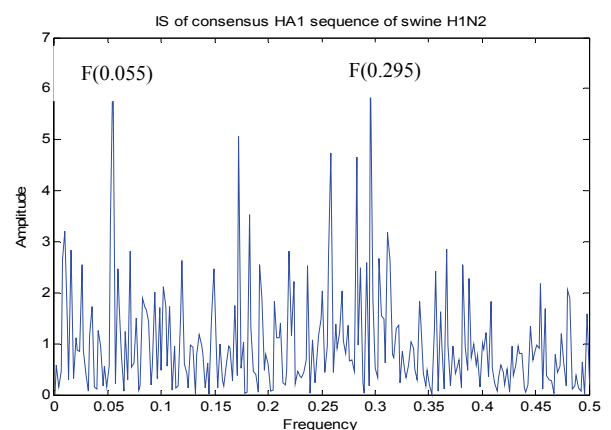

(b)

Figure 7. (a) IS of consensus HA1 sequence of 2009 H1N1. (b) IS of consensus HA1 sequence of swine H1N2.

Mutations in the binding site not only could modulate receptor specificity but also the antigenicity of the virus [27]. It was generally believed that the key residues at the binding site were not subject to selection, but recently a strong positive selection at position 190 in HA of H1N1 was detected in [13]. It was observed that there 
Table 8. Changes of amplitudes of IS frequencies by each mutation between swine and human binding patterns in HA1 of swine H1N2.

\begin{tabular}{|c|c|c|c|c|}
\hline \multirow[b]{2}{*}{ Mutations } & \multicolumn{2}{|c|}{$\begin{array}{l}\text { Mutating Consensus HA1 } \\
\text { Sequence of Swine } \\
\text { Binding Patterns }\end{array}$} & \multicolumn{2}{|c|}{$\begin{array}{l}\text { Mutating Consensus HA1 } \\
\text { Sequence of Human } \\
\text { Binding Patterns }\end{array}$} \\
\hline & $\Delta \mathrm{A}[\mathrm{F}(0.055)] \%$ & $\Delta \mathrm{A}[\mathrm{F}(0.295)] \%$ & $\Delta \mathrm{A}[\mathrm{F}(0.055)] \%$ & $\Delta \mathrm{A}[\mathrm{F}(0.295)] \%$ \\
\hline V47I & -0.45253 & -0.39918 & 0.61877 & 0.4217 \\
\hline $\mathrm{I} 71 \mathrm{~F}$ & -7.4498 & 3.7605 & 9.5403 & -3.7394 \\
\hline E127D & -11.057 & -1.2554 & 14.693 & 3.0055 \\
\hline $\mathrm{R} 131 \mathrm{~K}$ & 0 & 0 & 0 & 0 \\
\hline G170E & 0.014238 & -0.07755 & -0.01469 & 0.07289 \\
\hline N184T & -8.3652 & -10.1 & 11.495 & 10.475 \\
\hline R189Q & -1.4448 & -2.6783 & 1.6451 & 2.6875 \\
\hline T190S & -1.1476 & 0.1999 & 1.352 & -0.09641 \\
\hline $\mathrm{T} 211 \mathrm{~K}$ & -6.1626 & 6.441 & 8.1349 & -6.0602 \\
\hline $\mathrm{K} 216 \mathrm{~T}$ & -1.9443 & 7.4225 & 2.3502 & -6.895 \\
\hline E224A & -0.10535 & -1.9348 & 0.42226 & 1.7602 \\
\hline $\mathrm{A} 250 \mathrm{~V}$ & -1.1944 & -3.5238 & 1.8901 & 3.4949 \\
\hline $\mathrm{P} 271 \mathrm{~S}$ & -2.8719 & 3.2365 & 3.4537 & -3.3317 \\
\hline $\mathrm{K} 278 \mathrm{~T}$ & -0.95454 & 0.60359 & 2.0448 & -0.81079 \\
\hline Total & -43.1358 & 1.6950 & 57.6254 & 0.9842 \\
\hline
\end{tabular}

Table 9. Changes of amplitudes of IS frequencies by each mutation between consensus HA1 sequences of 2009 H1N1 and swine H1N2.

\begin{tabular}{ccccc}
\hline & Mutating Consensus HA1 Sequence of Swine H1N2 & Mutating Consensus HA1 Sequence of 2009 H1N1 \\
\hline Mutations & $\Delta \mathrm{A}[\mathrm{F}(0.055)] \%$ & $\Delta \mathrm{A}[\mathrm{F}(0.295)] \%$ & $\Delta \mathrm{A}[\mathrm{F}(0.055)] \%$ & $\Delta \mathrm{A}[\mathrm{F}(0.295)] \%$ \\
\hline K36R & -5.6796 & 5.4297 & 7.2412 & -4.7622 \\
$\mathrm{I} 61 \mathrm{~L}$ & 0 & 0 & 0 & 0 \\
S71F & -0.75109 & 0.59143 & 0.90722 & -0.85027 \\
S84N & -7.0341 & -8.3814 & 9.614 & 10.052 \\
D97N & -4.8444 & -9.6342 & 6.0451 & 9.9181 \\
T120E & -8.911 & 5.4563 & 11.964 & -7.0032 \\
K130R & -4.3521 & -4.4943 & 6.0754 & 5.9088 \\
K142N & 0.67563 & -2.0369 & -0.36048 & 2.8758 \\
K146R & -5.7743 & -2.0864 & 7.4097 & 1.4689 \\
D168N & 4.5193 & -5.5381 & -5.7447 & 4.824 \\
G170E & 0.011884 & -0.07133 & -0.01058 & 0.06883 \\
R205H & 1.7024 & 1.1275 & -2.4361 & -2.3933 \\
K211T & 6.5905 & -5.7011 & -7.8044 & 6.4193 \\
I216K & -1.8394 & 3.6983 & 2.0037 & -3.8566 \\
E224A & -0.2376 & -1.7644 & 0.61948 & 1.4082 \\
K239T & -5.1394 & 0.52104 & 6.8924 & 0.89224 \\
M257L & 8.8688 & -8.1637 & -10.571 & 10.056 \\
E258K & -2.8787 & -2.2561 & 3.7825 & 2.0134 \\
N260G & -0.05099 & 0.1242 & -0.071321 & -0.12802 \\
A261S & 1.0216 & 0.76162 & -0.593 & -1.5978 \\
I298V & 0.093799 & 0.2947 & -0.08087 & -0.42787 \\
K302E & -3.1322 & 1.8998 & 4.0108 & -1.4074 \\
L314M & -4.0997 & 6.3337 & -5.2087 \\
V321I & -0.49821 & -0.48678 & 0.3078 & 0.49537 \\
Total & -31.7389 & -27.3764 & 0.6555 & 28.7656 \\
\hline
\end{tabular}

were two distinct evolutionary patterns in host-driven antigenic drift of human H1N1 HAs at positions 190 and 225 , i.e., the antigenic drift of 1918 pandemic HAs occurred at position 225, and that of epidemic HAs hap- pened at position 190. In contrast to these two trends, the HAs in 2009 H1N1 took a different path, which were highly conserved at both positions 190 and 225 , based on the 73 HA sequences of 2009 H1N1, as of July 10, 
2009. In the present study, as of November 20, 2009, we had the following counts of various mutations at positions 190 and 225 in HA of 2009 H1N1 (Table 10). It appeared that the 2009 H1N1 HAs continued to keep this evolutionary pattern.

The alteration of receptor binding specificity was believed to be an essential step in host adaptation. Several studies on 1918 HA discovered that a single mutation D225G decreased the binding affinity of 1918 HA for $\alpha 2,6$ receptors and resulted in a mixed $\alpha 2,6 / \alpha 2,3$ binding virus, furthermore, a double mutations D190E/D225G abolished the binding of 1918 HA to $\alpha 2,6$ and resulted in a $\alpha 2,3$ binding virus $[28,29]$. Our numerical analysis (Table 11) suggested that the mutations at positions 190 and 225 would produce similar binding affinity of 2009 H1N1 HA to that of 1918 HA. Mutation D190E de-

Table 10. Mutation counts in HA1 sequences of 2009 H1N1.

\begin{tabular}{cc}
\hline Mutation & Counts \\
\hline D190G & 1 \\
D190V & 5 \\
D225E & 6 \\
D225G & 7 \\
D225N & 2 \\
\hline
\end{tabular}

Table 11. Changes of amplitudes of IS frequencies by mutations observed in HA1 sequences of 2009 H1N1.

\begin{tabular}{|c|c|c|c|}
\hline \multicolumn{4}{|c|}{$\begin{array}{l}\text { Mutating Consensus HA1 } \\
\text { Sequence of } 2009 \text { H1N1 }\end{array}$} \\
\hline Mutations & $\Delta \mathrm{A}[\mathrm{F}(0.055)] \%$ & $\Delta \mathrm{A}[\mathrm{F}(0.295)] \%$ & $\begin{array}{l}\text { Dominant } \\
\text { Peak } \\
\text { Frequency }\end{array}$ \\
\hline D190E & -2.0061 & -9.6206 & $\mathrm{~F}(0.282)$ \\
\hline D190G & -2.0302 & -9.6888 & $\mathrm{~F}(0.282)$ \\
\hline D190N & -2.0789 & -9.8255 & $\mathrm{~F}(0.282)$ \\
\hline D190V & -2.0027 & -9.6109 & $\mathrm{~F}(0.282)$ \\
\hline $\mathrm{D} 225 \mathrm{E}$ & -9.5672 & -2.1233 & $F(0.295)$ \\
\hline D225G & -9.6345 & -2.1488 & $\mathrm{~F}(0.295)$ \\
\hline $\mathrm{D} 225 \mathrm{~N}$ & -9.7694 & -2.2003 & $\mathrm{~F}(0.295)$ \\
\hline D190E,D225E & -10.5225 & -12.3705 & $\mathrm{~F}(0.282)$ \\
\hline D190E,D225G & -10.5836 & -12.3981 & $F(0.282)$ \\
\hline D190E,D225N & -10.7061 & -12.4537 & $\mathrm{~F}(0.282)$ \\
\hline D190G,D225E & -10.5392 & -12.4420 & $\mathrm{~F}(0.282)$ \\
\hline D190G,D225G & -10.6002 & -12.4696 & $\mathrm{~F}(0.282)$ \\
\hline D190G,D225N & -10.7226 & -12.5253 & $\mathrm{~F}(0.282)$ \\
\hline D190N,D225E & -10.5729 & -12.5854 & $\mathrm{~F}(0.282)$ \\
\hline D190N,D225G & -10.6338 & -12.6131 & $\mathrm{~F}(0.282)$ \\
\hline D190N,D225N & -10.7560 & -12.6688 & $\mathrm{~F}(0.282)$ \\
\hline D190V,D225E & -10.5201 & -12.3603 & $\mathrm{~F}(0.282)$ \\
\hline D190V,D225G & -10.5812 & -12.3879 & $\mathrm{~F}(0.282)$ \\
\hline D190V,D225N & -10.7037 & -12.4435 & $\mathrm{~F}(0.282)$ \\
\hline
\end{tabular}

creased the amplitude at frequency $\mathrm{F}(0.295)$ more than that at frequency $\mathrm{F}(0.055)$, displaying the avian binding affinity, while mutation D225G produced the opposite effect, exhibiting the human binding specificity. The double mutations D190E/D225G showed avian binding preference.

\subsubsection{Avian H5N1 and Human H5N1}

Most of the highly pathogenic avian H5N1 strains bind strongly to avian receptors. This specificity is normally a barrier to viral transmission from birds to humans. However, a few of them have been discovered to bind to human receptors as well as to avian receptors. The comparison of the consensus HA1 sequences of avian H5N1 and human H5N1 identified three mutations, R140K, $\mathrm{R} 189 \mathrm{~K}$, and T263A, and their impact on the two characteristic frequencies $\mathrm{F}(0.076)$ and $\mathrm{F}(0.236)$ was illustrated in Table 12.

As demonstrated in the experiments conducted in references [5,6], substitutions Q192R and S223L could mediate a shift from avian to human binding preference in the H5N1 viruses. In references [30,31,32], mutations Q226L and G228S enhanced the human binding capacity while reduced avian binding capacity of the $\mathrm{H} 5 \mathrm{~N} 1$ viruses. Here the ISM was utilized to evaluate the outcome of these mutations (Table 13). Figure 8 illustrated the effect of mutation S223L on the two characteristic frequencies $\mathrm{F}(0.076)$ and $\mathrm{F}(0.236)$.

\section{DISCUSSION}

Understanding the minimal adaptive changes necessary for viral adaptation to human host is of key importance in learning how pandemic influenza viruses emerge. Alteration of receptor recognition is a vital step in host adaptation, which is modulated directly by a subset of amino acids present in the HA protein. Other determinants of host adaptation include continued viral evolution to improve transmission and replication efficiency and optimize tissue tropism.

There are several well-known mutations in HA protein in different flu subtypes, playing critical roles in receptor binding preference shift. Besides mutations in $\mathrm{HA}$, the glycosylation sites in HA might also impact the binding specificity of HA [32]. The mutations discovered in this study represent alternatives by which the HA can switch its substrate recognition. These mutations occur in nature, whereas those artificially engineered by wet lab techniques may have a very low probability to occur in nature. As evidenced by the study in [30] that mutations Q226L and G228S in HA proteins could alter the binding specificity of the H5N1 viruses. Nevertheless, it also pointed out that the likelihood to acquire the necessary nucleotide changes to produce these mutations in natural virus is small, which could explain in part why 
Table 12. Changes of amplitudes of IS frequencies by each mutation between consensus HA1 sequences of avian H5N1 and human H5N1.

\begin{tabular}{ccccc}
\hline & \multicolumn{2}{c}{$\begin{array}{c}\text { Mutating Consensus } \\
\text { HA1 Sequence } \\
\text { of Avian H5N1 }\end{array}$} & \multicolumn{2}{c}{$\begin{array}{c}\text { Mutating Consensus } \\
\text { HA1 Sequence } \\
\text { of Human H5N1 }\end{array}$} \\
\hline Mutation & $\Delta \mathrm{A}[\mathrm{F}(0.076)] \%$ & $\Delta \mathrm{A}[\mathrm{F}(0.236)] \%$ & $\Delta \mathrm{A}[\mathrm{F}(0.076)] \%$ & $\Delta \mathrm{A}[\mathrm{F}(0.236)] \%$ \\
\hline R140K & 7.9425 & -4.5900 & -7.8143 & 5.2052 \\
R189K & -0.5253 & 7.7370 & 0.2142 & -7.9896 \\
T263A & -3.7894 & -6.0611 & 4.5619 & 6.8405 \\
Total & 3.6278 & -2.9141 & -3.0382 & 4.0561 \\
\hline
\end{tabular}

Table 13. Changes of amplitudes of IS frequencies by mutations experimented in references [5,6,30,31,32].

\begin{tabular}{ccc}
\hline & \multicolumn{2}{c}{$\begin{array}{c}\text { Mutating Consensus HA1 } \\
\text { Sequence of Avian H5N1 }\end{array}$} \\
\hline Mutations & $\Delta \mathrm{A}[\mathrm{F}(0.076)] \%$ & $\Delta \mathrm{A}[\mathrm{F}(0.236)] \%$ \\
\hline Q192R & -3.2185 & 1.5596 \\
S223L & -4.0399 & 10.8075 \\
Q192R, S223L & -6.5711 & 11.6823 \\
Q226L & 0.9498 & 17.4463 \\
G228S & 7.3516 & 15.7656 \\
Q226L, G228S & 8.0339 & 16.9010 \\
\hline
\end{tabular}

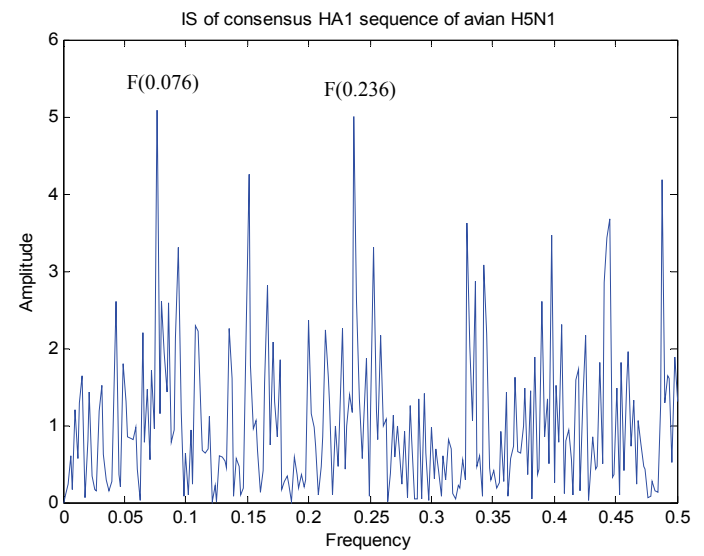

(a)

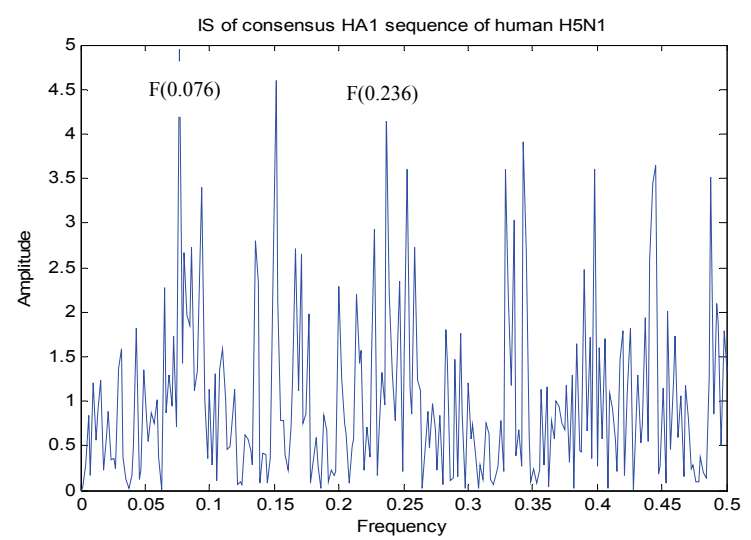

(b)

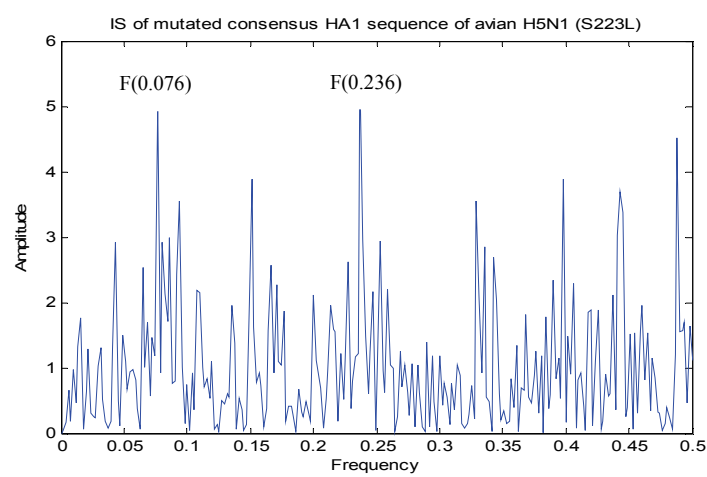

(c)

Figure 8. (a) IS of consensus HA1 sequence of avian H5N1; (b) IS of consensus HA1 sequence of human $\mathrm{H} 5 \mathrm{~N} 1$; (c) IS of consensus HA1 sequence of avian H5N1 mutated by S223L.

viruses such as H5N1 have not yet evolved into human transmissible strains to cause a human pandemic.

It appears that increased binding affinity for human influenza receptors alone is not sufficient for efficient human transmission, and additional molecular determinants are required. In [33], it was proposed that binding to long-chain $\alpha 2-6$ sialosides is a necessary requirement for viruses to efficiently replicate and transmit in humans. There is inadequacy in assessing the adaption to human receptor affinity from the analysis of a few influenza strains [30]. It showed that the effects of the same mutations, such as Q226L/G228S, on the binding preference of one strain were not the same on others strains in H5N1. Because lab experiments are labor intensive and costly, bioinformatics approaches offer reasonable alternatives in the analysis of binding specificity given the large number of virus sequences, which can process all strains with any combination of mutations within a subtype efficiently.

\section{CONCLUSIONS}

The increasing trend of direct transmission of avian/ swine influenza viruses to humans underscores the need to understand further the mechanism of glycan receptor recognition and specificity switch. In this study, muta- 
tions in HA1 within or between hosts in various flu subtypes were identified, and their contribution to binding preference was measured using the ISM. Our numerical analysis implied that the mutations in HA1 of $2009 \mathrm{hu}-$ man $\mathrm{H} 1 \mathrm{~N} 1$ collectively tended to reduce the swine binding affinity in the seasonal H1N1 strains and to increase that in the pandemic H1N1 strains. At the same time, they increased the human binding affinity in the pandemic H1N1 strains and had little impact on that in the seasonal H1N1 strains. The mutations in HA1 of avian $\mathrm{H} 5 \mathrm{~N} 1$ and avian $\mathrm{H} 1 \mathrm{~N} 1$ exhibited reduced avian binding in the strains of avian binding propensity while showed enhanced avian binding affinity in the strains with human binding propensity. They displayed the opposite effects on human binding. The mutations in HA1 of swine H1N2 reduced the swine binding affinity in the strains with swine binding propensity and enhanced that in the strains with human binding propensity. They showed little impact on the human binding affinity, which was different from the mutations in HA1 of 2009 H1N1. The mutations between the consensus HA1 sequences of $2009 \mathrm{H} 1 \mathrm{~N} 1$ and swine H1N2 decreased both the human and swine binding affinities in swine H1N2 and increased those in $2009 \mathrm{H} 1 \mathrm{~N} 1$. The mutations between the consensus HA1 sequences of human H5N1 and avian $\mathrm{H} 5 \mathrm{~N} 1$ increased the avian binding affinity and decreased the human binding affinity in avian $\mathrm{H} 5 \mathrm{~N} 1$ while produced the opposite effects on those in human H5N1.

The mutations discovered in the present study confirmed the potential for influenza viruses to adapt to human host, and furthermore, our numerical analysis detailed the extent of binding preference changes induced by each mutation. These mutations and their corresponding contribution to the binding specificity alteration yielded new clues to the mechanism of receptor recognition switch within and between hosts. The ISM offered a complementary and efficient approach to investigate the binding affinities of all HA sequences in various subtypes, a task difficult to accomplish experimentally.

\section{ACKNOWLEDGMENTS}

We thank Houghton College for its financial support.

\section{REFERENCES}

[1] Webster, R.G. (1999) 1918 Spanish influenza: The secrets remain elusive. Proceedings of the National Academy of Sciences, USA, 96(4), 1164-1166.

[2] Li, Q., Kash, J.C., Dugan, V.G., Wang, R.X., Jin, G.Z., Cunningham, R.E. and Taubenberger, J.K. (2009) Role of sialic acid binding specificity of the 1918 influenza virus hemagglutinin protein in virulence and pathogenesis for mice. Journal of Virology, 83(8), 3754-3761.

[3] Matrosovich, M.N., Klenk, H. D. and Kawaoka, Y. (2006)
Receptor specificity, host-range, and pathogenicity of influenza viruses. In Yoshihiro Kawaoka (ed.) Influenza Virology: Current Topics, Caister Academic Press, 95-137.

[4] Zambon, M. (2007). Lessons from the 1918 influenza. Nature Biotech, 25, 433-434.

[5] Gambaryan, A. Tuzikov, A., Pazynina, G., Bovin, N., Balish, A. and Klimov, A. (2006) Evolution of the receptor binding phenotype of influenza A (H5) viruses. Virology, 344(2), 432-438.

[6] Yamada, S., Suzuki, Y., Suzuki, T., Le, M. Q., Nidom, C. A., Sakai-Tagawa, Y., Muramoto, Y., et al. (2006) Haemagglutinin mutations responsible for the binding of H5N1 influenza A viruses to human-type receptors. $\mathrm{Na}$ ture, 444(7117), 378-382.

[7] Matrosovich, M., Tuzikov, A., Bovin, N., Gambaryan, A., and Klimov, A., et al. (2000) Early alterations of the receptor-binding properties of $\mathrm{H} 1, \mathrm{H} 2$, and $\mathrm{H} 3$ avian influenza virus hemagglutinins after their introduction into mammals. Journal of Virology, 74(18), 8502-8512.

[8] Bateman, A.C., Busch, M.G., Karasin, A.I., Bovin, N., and Olsen, C.W. (2008) Amino acid 226 in the hemagglutinin of H4N6 influenza virus determines binding affinity for alpha2, 6-linked sialic acid and infectivity levels in primary swine and human respiratory epithelial cells. Journal of Virology, 82(16), 8204-8209.

[9] Wan, H., Sorrell, E.M., Song, H., Hossain, M.J., Ramirez-Nieto, G., et al. (2008) Replication and transmission of H9N2 influenza viruses in ferrets: Evaluation of pandemic potential. PLoS ONE, 3(8), e2923.

[10] Rogers, G.N. and D'Souza, B.L. (1989) Receptor binding properties of human and animal H1 influenza virus isolates. Virology, 173, 317-322.

[11] Matrosovich, M.N., Gambaryan, A.S., Teneberg, S., Piskarev, V.E., Yamnikova, S.S., et al. (1997) Avian influenza A viruses differ from human viruses by recognition of sialyloligosaccharides and gangliosides and by a higher conservation of the HA receptor-binding site. $\mathrm{Vi}$ rology, 233(1), 224-234.

[12] Reid, A.H., Janczewski, T.A., Lourens, R.M., Elliot, A.J., Daniels, R.S., Berry, C.L., Oxford, J.S. and Taubenberger, J.K. (2003) 1918 influenza pandemic caused by highly conserved viruses with two receptor-binding variants. Emerg Infect Disease, 9(10), 1249-1253.

[13] Shen, J., Ma, J. and Wang, Q. (2009) Evolutionary trends of A(H1N1) influenza virus hemagglutinin since 1918. PLoS ONE, 4(11), e7789.

[14] Srinivasan, A., Viswanathan, K., Raman, R., Chandrasekaran, A., Raguram, S., Tumpey, T.M., Sasisekharan, V. and Sasisekharan, R. (2008) Quantitative biochemical rationale for differences in transmissibility of 1918 pandemic influenza A viruses. Proceedings of the National Academy of Sciences, 105(8), 2800-2805.

[15] Soundararajan, V., Tharakaraman, K., Raman, R., Raguram, S., Shriver, Z., Sasisekharan, V. and Sasisekharan R. (2009) Extrapolating from sequence-the 2009 H1N1 "swine" influenza virus. Nature Biotechnology, 27(6), 510-513.

[16] Childs, R.A., Palma, A.S., Wharton, S., Matrosovich, T., Liu, Y., Chai, W.G., Campanero-Rhodes, M.A., Zhang, Y.B., Eickmann, M., Kiso, M., Hay, A., Matrosovich. M. and Feizi, T. (2009) Receptor-binding specificity of 
pandemic influenza A (H1N1) 2009 virus determined by carbohydrate microarray. Nature Biotechnology, 27 (9), 797-799.

[17] $\mathrm{Hu}, \mathrm{W}$. (2009) Analysis of correlated mutations, stalk motifs, and phylogenetic relationship of the 2009 influenza A virus neuraminidase sequences. Journal of Biomedical Science and Engineering, 2(7), 550-558.

[18] Hu, W. (2010) The Interaction between the 2009 H1N1 influenza A hemagglutinin and neuraminidase: Mutations, co-mutations, and the NA stalk motifs. Journal of Biomedical Science and Engineering, 3, 1-12.

[19] Veljkovic, V., Niman, H.L., Glisic, S., Veljkovic, N., Perovic, V. and Muller C.P. (2009). Identification of hemagglutinin structural domain and polymorphisms which may modulate swine H1N1 interactions with human receptor. BMC Structural Biology, 9, 62.

[20] Veljkovic, V., Veljkovic, N., Muller, C.P., Müller, S. Glisic, S., Perovic, V. and Köhler, H. (2009) Characterization of conserved properties of hemagglutinin of H5N1 and human influenza viruses: Possible consequences for therapy and infection control. BMC Structural Biology, 7, 9-21.

[21] Cosic, I. (1997) The resonant recognition model of macromolecular bioreactivity, theory and application. Berlin: Birkhauser Verlag.

[22] $\mathrm{Hu}, \mathrm{W}$. (2010) Identification of highly conserved domains in hemagglutinin associated with the receptor binding specificity of influenza viruses: 2009 H1N1, avian H5N1, and swine. Journal of Biomedical Science and Engineering, 3, 114-123.

[23] Katoh, K., Kuma, K., Toh, H. and Miyata, T. (2005) MAFFT version 5: Improvement in accuracy of multiple sequence alignment. Nucleic Acids Research, 33(2), 511518.

[24] MacKay, D. (2003) Information theory, inference, and learning algorithms. Cambridge University Press.

[25] KováccaronOVá, A., Ruttkay-Nedecký, G., Karol HaverlíK, I. and Janecccaronek, S. (2002) Sequence similarities and evolutionary relationships of influenza virus A hemagglutinins, Virus Genes, 24(1), 57-63.

[26] Gamblin, S.J., Haire, L.F., Russell, R.J., Stevens, D.J., Xiao, B., Ha, Y., et al. (2004) The structure and receptor binding properties of the 1918 influenza hemagglutinin. Science, 303, 1838-1842.

[27] Daniels, R.S., Douglas, A.R., Skehel, J.J., Wiley, D.C., Naeve, C.W., Webster, R.G., Rogers, G.N. and Paulson, J. C. (1984). Antigenic analyses of influenza virus haemagglutinins with different receptorbinding specificities. Virology, 138, 174-177.

[28] Srinivasan, A., Viswanathan, K., Raman, R., Chandrasekaran, A., Raguram, S., et al. (2008) Quantitative biochemical rationale for differences in transmissibility of 1918 pandemic influenza A viruses. Proceedings of the National Academy of Sciences, 105, 2800-2805.

[29] Stevens, J., Blixt, O., Glaser, L., Taubenberger, J.K. , Palese, P., et al. (2006) Glycan microarray analysis of the hemagglutinins from modern and pandemic influenza viruses reveals different receptor specificities. Journal of Molecular Biology, 355(5), 1143-1155.

[30] Ayora-Talavera, G., Shelton, H., Scull, M.A., Ren, J., Jones, I.M., et al. (2009) Mutations in H5N1 influenza virus hemagglutinin that confer binding to human tracheal airway epithelium. PLOS ONE, 4(11), e7836.

[31] Stevens, J., Blixt, O., Glaser, L., Taubenberger, J.K., Palese, P., et al. (2006) Glycan microarray analysis of the hemagglutinins from modern and pandemic influenza viruses reveals different receptor specificities. Journal of Molecular Biology, 355(5), 1143-1155.

[32] Stevens, J., Blixt, O., Chen, L.M., Donis, R.O., Paulson, J.C., et al. (2008) Recent avian H5N1 viruses exhibit increased propensity for acquiring human receptor specificity. Journal of Molecular Biology, 381(5), 1382- 1394.

[33] Chandrasekaran, A., Srinivasan, A., Raman, R., Viswanathan, K., Raguram, S., Tumpey, T.M., Sasisekharan, V. and Sasisekharan, R. (1008) Glycan topology determines human adaptation of avian $\mathrm{H} 5 \mathrm{~N} 1$ virus hemagglutinin. Nature Biotechnology, 26(1), 107-113. 